\title{
Semicircular Lipoatrophy: An Electrostatic Hypothesis
}

\author{
Rafael Linares-García Valdecasas ${ }^{a}$ Esther Cuerda-Galindo ${ }^{a}$ \\ Julio Ramiro Bargueño ${ }^{b}$ Pablo Naranjo Garciac Daniel Vogelfrang-Garncarz ${ }^{d}$
}

M. Angustias Palomar-Gallego ${ }^{a}$

Departments of a Human Anatomy and Embryology and ${ }^{b}$ Signal Theory and Communication, Universidad Rey

Juan Carlos, ' Elite Laser, and ${ }^{\mathrm{d}}$ Centro de Estudios Vasculares, Madrid, Spain

\section{Key Words \\ Lipoatrophia semicircularis - Semicircular lipoatrophy . \\ Electrostatic charge - Electromagnetic field - Fat tissue}

ic environment all of them improved, we can conclude that electrostatic charges but not electromagnetic ones are the main cause of SL.

\begin{abstract}
Background: Semicircular lipoatrophy $(\mathrm{SL})$ is a benign pathology characterized by subcutaneous adipose tissue atrophy. Objective:To determine causes of SL. Methods: We performed research on 42 cases of SL who had developed symptoms of lipoatrophy with a technical study of the building and clinical study of the affected patients. Results: Electromagnetic field and electrostatic charge measurements were performed. No signals different from typical radio, TV and other wireless communication devices were recorded. Electrostatic charges were recorded in floors, environments and on different furniture; they were positive, and all charges disappeared on contact with the worker's skin. Data about the workplace were collected, and clinical examinations were performed, including blood and biochemistry tests and 18 ultrasound skin tests. Conclusions: As no abnormal electromagnetic measurements were found and electrostatic changes and occupational behaviors showed some relevant data and as after changes in order to control the electrostat-
\end{abstract}

\section{Introduction}

Semicircular lipoatrophy (SL) is a benign and reversible pathology characterized by subcutaneous tissue atrophy, which affects subcutaneous adipose tissue and related structures, and is located mainly in the thigh region [1]. It was first described in 1974 [2, 3] and is characterized by the appearance of semicircular bands, unilateral or bilateral, depressed, usually located in the anterior and lateral region of the thigh, and at an approximate height of $72 \mathrm{~cm}$ from the ground. SL has occasionally been noted to appear in other areas, such as the forearms [4] or ankles [5]. It affects women more frequently than men, having a ratio of $6: 1$. However, the higher occurrence in women might be because of greater aesthetic concerns, which lead women to look for a medical solution, or perhaps because female subcutaneous tissue has a predisposition to this particular pathology $[6,7]$. The etiology of

\section{KARGER 125}

(c) 2015 S. Karger AG, Base

$1018-8665 / 15 / 2303-0222 \$ 39.50 / 0$

E-Mail karger@karger.com

www.karger.com/drm
Dr. Rafael Linares-García Valdecasas

Department of Human Anatomy and Embryology

Universidad Rey Juan Carlos, Avda Atenas s/n

ES-28922 Alcorcón, Madrid (Spain)

E-Mail rafael.linares@urjc.es 
Table 1. Data collected from workers' interviews

\begin{tabular}{llr}
\hline Lesion location & $1 / 3$ lower thigh & $\begin{array}{r}2 \text { patients } \\
16 \text { patients }\end{array}$ \\
\hline Touching objects & yes & 15 patients \\
suffer discharge & no & 3 patients \\
\hline Clothing type & pants & 14 patients \\
& skirts & 4 patients \\
& slim & 7 patients \\
& regular & 11 patients \\
& natural fiber & 13 patients \\
& synthetic fiber & 12 patients \\
\hline Use footrest & yes & \\
& no \\
\hline
\end{tabular}

the condition is poorly understood and is probably multifactorial $[8,9]$. Several hypotheses have been suggested. Some authors, such as Bloch and Runne [10], argue that the cause is an abnormality of the lateral femoral circumflex artery, which when joined with repeated microtrauma can cause ischemic atrophy of fat tissue. This hypothesis is about a very rare abnormality ( $3 \%$ of the population) and therefore cannot be taken into account with respect to the frequent occurrences of SL that have been reported for the last 10 years or so in some office buildings. Another theory explains the lesions as a result of repeated microtrauma in certain jobs $[11,12]$ and a maintained pressure in the affected areas caused by closefitting clothes $[13,14]$. SL has also been associated with exposure to electromagnetic fields generated by wires or antennas in the work environment, and the accumulation of electrostatic charges on office devices such as printers, computers and tables. This is suggested to produce changes in intrinsic bioelectric properties of the skin, activating macrophages that produce lipophagia [15-18].

The designs of new office buildings, with enclosed spaces and large windows (greenhouse effect), make it necessary to use cooling systems that modify the relative humidity. This causes an apparent change in a material's conductivity by the appearance of a surface density electrostatic charge. Low levels of relative humidity favor the presence of such charges. Some authors suggest that these factors could make SL more frequent in newly designed buildings [15, 19-22]. In December 2010, an agreement between the Rey Juan Carlos University and BP Oil Spain was made to study SL, as some workers from the company had developed symptoms of lipoatrophy. This study was carried out in 2 phases. Phase 1 was a technical study of the building, and phase 2 was a clinical study of the affected workers.

\section{Material and Methods}

First Phase: Technical Study of the Building

Measurements were taken to check the electromagnetic and electrostatic state of the building. These measurements were developed with an isotropic broad-band antenna ( $30 \mathrm{MHz}$ to $3 \mathrm{GHz}$ ) (model R\&S ${ }^{\circledR}$ TS-EMF; Rohde \& Schwarz, Munich, Germany) and a Spectrum Handheld Analyzer R\&S ${ }^{\circledR} \mathrm{FSH}-3$, and were performed on all floors of the building with greater emphasis on the areas where affected workers were located. Electrostatic charges were measured using an electrostatic meter with a measuring range of $\pm 0-20 \mathrm{kV}$ (model 990.10282 ${ }^{\circledR}$; Electrostática, Barcelona, Spain). All measurements were performed on different floors, in different environments and on different furniture.

\section{Second Phase: Clinical Study}

During this phase, volunteer workers who had presented with lesions compatible with lipoatrophy were examined. We conducted exhaustive interviews where we collected personal and family backgrounds, and focused especially on obtaining data about the appearance, location, symptoms, duration and resolution of lesions. Data about the workplace were collected, including posture, use of a footrest when working, type of clothing worn and sensation of discharge when touching some objects. Clinical examinations were performed, including blood and biochemistry tests, and some patients also underwent an ultrasound skin test.

\section{Results}

The company had 390 workers in total, 182 male and 208 female; age was similar in both groups; 42 of them had lesions clinically compatible with lipoatrophy (defined as a band of semicircular subcutaneous fat atrophy), mostly located on the anterior surface of the thigh about 75$80 \mathrm{~cm}$ above the ground, except 2 patients whose lesions were about $10 \mathrm{~cm}$ above the knee $(65 \mathrm{~cm}$ above the ground). All those affected were women (table 1). The condition had remitted spontaneously in 24 workers after they had had some holidays and had been away from their workplace (and not submitted to the electrostatic environment of the building), and 18 workers still showed some SL signs.

Electromagnetic field measurements were performed throughout the building during work time focusing on the areas where the affected workers' offices were located. The electromagnetic environment was the same for all the patients. The electrostatic charges measured in different 
Fig. 1. Electromagnetic signal (S) measurements inside the office building at working hours.

Fig. 2. Exposure levels of electromagnetic signals (S) allowed by Spanish Law to protect the public radioelectric space (http:// www.boe.es/boe/dias/2002/01/12/pdfs/ A01528-01536.pdf).
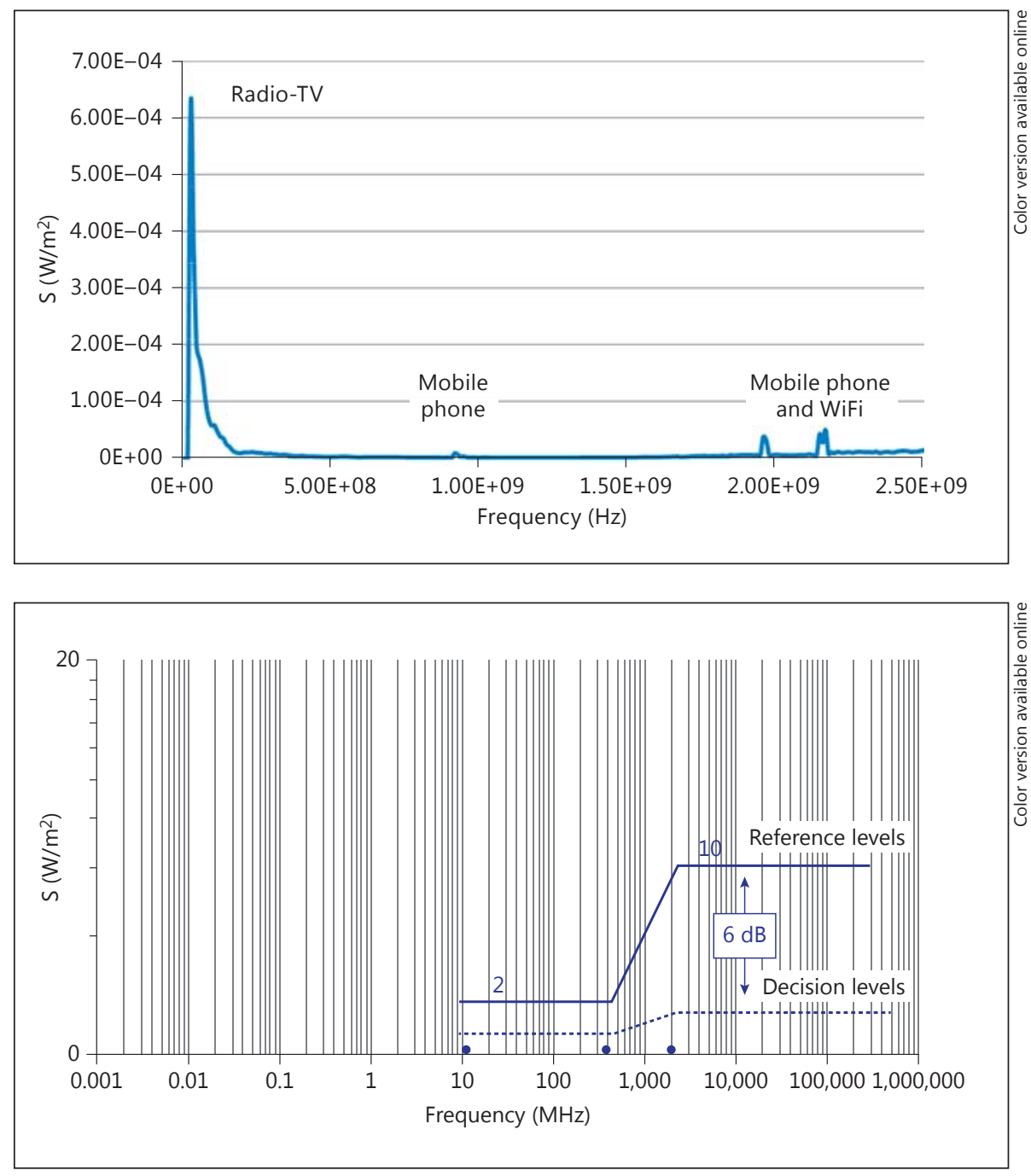

places (workers with SL and workers without SL) were the same everywhere. No signals different from typical radio, $\mathrm{TV}$ and other wireless communication devices, such as mobile phones and WiFi (fig. 1), were recorded, and were not at levels above that prescribed by law (fig. 2). Electrostatic charge measurements were recorded as the potential difference generated by the accumulation of the electrostatic charge or 'volt' on measuring equipment of $\pm 20 \mathrm{kV}$. All furniture was found to be properly grounded. Measurements of desks showed no electrostatic charge. However, measurements of chairs, both in seats and in rear seat backs, but especially seats, showed an electrostatic charge accumulation (table 2).

Electrostatic charge measurements from different types of footrests were taken. Plastic facilitates generation and accumulation of electrostatic charges more than materials which are coated with a layer of carpet, fabric or felt. Measurements of screens in the workplace were performed, and no electrostatic charge accumulation was found. In most cases, screens were flat screen monitors, which minimize the risk of charges. Electrostatic charges were recorded when measuring the output trays of printers and freshly printed sheets from laser printing equipment and copiers. Charges disappeared on contact with the worker's skin. Carpeted floors were measured, and no significant electrostatic charges were recorded. The antistatic effect of carpet was evident.

As an additional measure, we raised part of the false floor and obtained electrostatic charge data on wiring areas, with no significant values being recorded. We also found no outstanding values after electromagnetic field measurements and concluded that the false floor was electromagnetic field isolated. 
The relative humidity in each floor should not be less than $50 \%$. Data from building sensors showed the relative humidity to be routinely closer to 45 than $50 \%$, allowing the consequent risk of an accumulation of electrostatic charges.

On clinical examination we distinguished 2 groups of patients: (1) those who reported lesions which had resolved $(\mathrm{n}=24)$, either spontaneously or because of a change of workplace, and (2) those who had clinical lesions at the time of the study $(\mathrm{n}=18)$. In the latter group, lesions affected the anterior thighs either unilaterally or bilaterally and consisted of linearly depressed areas, which were asymptomatic and had a width of $1-2 \mathrm{~cm}$ and a length of 3-7 cm. These lesions were more evident when patients stood up and with deep palpation. For all patients, complete blood counts and biochemical tests were conducted, and all parameters were within normal ranges. Eighteen patients agreed to be examined and underwent ultrasound of the affected skin: 9 showed SL, and 6 also had lipodystrophy (cellulite). The other 9 patients had only lipodystrophy. We decided to treat all $18 \mathrm{pa}-$ tients in the same way with changes in order to control the electroenvironment (table 3), and all of them improved, with remitting SL, and this condition has been maintained until now.

\section{Discussion}

The human body is a good conductor of electricity. In environments with low relative humidity, the body can accumulate electrostatic charges, with the potential to reach several thousand volts [23-26]. The type of clothes worn has a great influence on static electricity generation. For example, silks, wool and synthetic fibers are good producers of static electricity when friction is applied. Shoes, as possible grounding elements, play an important role in this phenomenon $[21,27]$.

Electrostatic discharges higher than $2 \mathrm{kV}$ are felt as an electric shock and give off energy of $0.4 \mathrm{~mJ}$. The use of the human body as a transmitter can be dangerous.

The choice of contact material is critical for the reduction of electrostatic charges generated by contact. It is important to avoid working with materials with very different electron affinities, meaning wide gaps in the triboelectric series (table 4), for example glass and Teflon (polytetrafluorethylene), or polyvinyl chloride and polyamide (nylon).

The magnitude of the electrostatic charge is related to the position or relative distance of the materials to each
Table 2. Data of electrostatic charges $(\mathrm{kV})$ obtained from furniture (maximum value of $20 \mathrm{kV}$ )

\begin{tabular}{lc}
\hline Carpet & 0 \\
Desk & $-0.03,-0.06$ \\
Laser printer & $0.68,0.76$ \\
Seat & $0.55,1.83$ \\
Back seat (low) & -0.09 \\
Back seat (high) & $0.41,-1.85$ \\
Footrest & $-0.84,-3.82$ \\
Wires under floor & $-0.07,-0.4$ \\
\hline
\end{tabular}

Table 3. Changes in order to control the electroenvironment

\begin{tabular}{ll}
\hline Ground wire & To earth the desk \\
\hline $\begin{array}{l}\text { Electrostatic } \\
\text { generators }\end{array}$ & $\begin{array}{l}\text { To avoid the use of a footrest under the desk } \\
\text { To use antistatic seats or connect them to the } \\
\text { ground }\end{array}$ \\
& $\begin{array}{l}\text { To avoid the use of 'hot lights' on the desk and to } \\
\text { favor 'cold lights' } \\
\text { To use antistatic carpets and floors } \\
\text { To group the laser printers and photocopiers in } \\
\text { special rooms, not on the desk }\end{array}$ \\
& $\begin{array}{l}\text { Control of the relative humidity, near values of } \\
\text { Climate } \\
\text { conditions }\end{array}$ \\
& $\begin{array}{l}\text { Control of temperature; the air conditioning is a } \\
\text { source of dry air which favors electrostatic energy }\end{array}$
\end{tabular}

Table 4. The triboelectric series

\section{CHARGE +}

Glass

Hair

Nylon

Wool

Skin

Aluminum

Polyester

Paper

Cotton

Steel

Copper

Nickel

Glue

Acrylic

Polyurethane

Polyvinyl chloride

Teflon

CHARGE - 
other in the series, and its sign is determined by the propensity of the material to transfer or gain electrons, which is what indicates the series. Reducing contact pressure between the materials can decrease the electrostatic transfer, with an adequate control of the temperature at the contact surfaces.

In the current study of the working environment we recorded high electrostatic charge levels in chairs, certain footrests and laser printers. The continuous friction between furniture, mostly chairs, and synthetic clothing in an environment with a relative humidity under $50 \%$ allowed for the accumulation of high electrostatic charge levels (with a potential of thousands of volts). The human body is an excellent electrical conductor and becomes a perfect way to release accumulated charges, especially through the more compressed areas or those parts of the body which have closer contact with clothes [12]. Clothes commonly worn by workers are made with synthetic fibers, silk, rayon or wool, and facilitate static charge accumulation $[13,24,28]$. Footwear usually contains rubber and has synthetic soles that do not permit the release of static energy into the ground, hence people remain charged. All these factors contribute to the release of the accumulated electrostatic charge through grounded objects with which the employee has contact, typically the desk $[26,29]$. The contact usually takes place when the legs touch the underside of the desktop, and the area between the hip and knee is the main place for discharging the charge to the ground. This charge accumulation and discharge phenomenon are repeated continuously throughout the working day.

Energy crossing through body tissue can occur anywhere, but preferentially it happens at surfaces that have higher contact pressure. In women wearing pants, this is the anterior face of the thighs. Pants are more easily adjusted in this region in women compared with men. In addition to this the fat tissue structure is different in women compared to men, and both can be a reason for the higher prevalence of SL being observed in women.

In the current study, 2 workers had lesions about $10 \mathrm{~cm}$ above the knee. These workers were the only 2 of all those interviewed who reported the regular use of skirts made of conductive fibers, and the end part of the skirt coincided with the place where the lesions were located. We believe that these lesions were located lower than usually occurs because, in the absence of any pressure area, discharge occurs from the final edge of the piece of clothing. No data were obtained that enabled us to assess whether lipoatrophy was caused by repeated microtrauma produced by the edge of tables, as this situation was not reported by interviewed workers. We believe that the unique reason for the location of lesions is from the highest pressure area of the clothes and the height of tables.

Our study, performed in patients suffering from SL due to adverse conditions in their work environment, supports the hypothesis previously published. Some authors such as Verschaeve and Maes [16] have performed investigations that suggest SL can be caused by 'electric' phenomena. Other authors [30] have performed studies in vivo with electrostatic discharge, and they conclude that more studies are needed, because it cannot be rejected that the current transfer is directly related to SL. We consider that in the present study, electrostatic energy is the main cause of SL, because we have concluded that removing electrostatic charge generation in the work environment leads to a clinical resolution of lesions and no new cases occur, demonstrating a clear cause-effect relation.

\section{Conclusion}

We present a study of SL with both technical measurements of the building and an epidemiological study of the affected workers. The results suggest that people at risk for developing SL are women wearing synthetic clothes, particularly short-sleeved shirts, stretch pants and shoes with rubber synthetic soles. The risk of developing SL at the workplace increases when office furniture does not include grounded desks, chairs are made of material that accumulates electrostatic charges, and the office has low relative humidity conditions.

The mechanism for generating lesions can be explained as follows: the worker is charged when seated on a chair, or when he or she takes a sheet of paper from the laser printer in a dry environment. The person's clothes and shoes are charged, and as they are not conductors, they do not allow for discharge to the ground. Discharge occurs when the worker contacts a grounded object that allows discharge, in this case the underside of the desktop. Clothing discharge is produced through the area where the pressure is highest because of the particular clothes worn, which usually coincides with the anterior region of the thighs.

We believe that the higher prevalence of SL seen in women can be explained, among other genetic reasons, by differences in the type of clothing worn. Men rarely wear stretch clothes and often wear long-sleeved shirts, so the clothes contacting the desktop dispel the electrostatic charge, bypassing the body of the worker. 


\section{Acknowledgments}

This study was carried out thanks to the collaboration between BP Oil Spain with Rey Juan Carlos University promoted by the Medical Service of BP Oil Spain concerned about the health of their employees.

\section{Disclosure Statement}

The authors declare that they have no competing interests.

\section{References}

$>1$ Nogue S, Sanz P, Tomas X, Farrús X: Lipoatrophy semicircularis. Med Clin (Barc) 2008; 130:360-360.

2 Gschwand WR, Munzberg H: Lipoatrophia semicircularis - linear circular atrophy of subcutaneous fat on extremities. Hautarzt 1974;25:222-227.

$>3$ Bachmeyer C, Haddad A: Lipoatrophia semicircularis of the thighs. Presse Med 2011;40: 980-981.

4 Pardal-Fernandez JM, Lopez-Villaescusa M, Rodriguez-Vazquez M: False amyotrophy in the forearms due to semicircular lipoatrophy. Rev Neurol 2013;56:443-444.

5 Dimson OG, Esterly NB: Annular lipoatrophy of the ankles. J Am Acad Dermatol 2006; 54(2 suppl):S40-S42.

6 Ayala F, Lembo G, Ruggiero F, Balato N: Lipoatrophia semicircularis - report of a case. Dermatologica 1985;170:101-103.

$\checkmark 7$ Perez A, Nebot M, Macia M, Panadés R: An outbreak of 400 cases of lipoatrophia semicircularis in Barcelona: effectiveness of control measures. J Occup Environ Med 2010;52: 751-757.

8 Gschwandtner WR, Munzberger H: Lipoatrophia semicircularis. Wien Klin Wochenschr 1975;87:164-168.

9 Gruber PC, Fuller LC: Lipoatrophy semicircularis induced by trauma. Clin Exp Dermatol 2001;26:269-271.

$>10$ Bloch PH, Runne U: Semicircular lipoatrophy in the male. Coincidence of arterial variations and micro-traumas as a possible disease cause (in German). Hautarzt 1978;29:270-272.

$>11$ Nagore E, Sanchez-Motilla JM, RodriguezSerna M, Vilata JJ, Aliaga A: Lipoatrophia semicircularis - a traumatic panniculitis: report of seven cases and review of the literature. J Am Acad Dermatol 1998;39:879-881.
12 Degroot AC: Is lipoatrophy semicircularis induced by pressure. Br J Dermatol 1994;131: 887-890.

13 Mascaro JM, Ferrando J: The perils of wearing jeans - lipoatrophia semicircularis. Int J Dermatol 1983;22:333.

14 Zafra-Cobo M I, Yuste-Chaves M, GarabitoSolovera E: Pressure-induced lipoatrophia semicircularis. Actas Dermosifiliogr 2008;99: 396-398.

15 Flagothier C, Quatresooz P, Pierard G: Electromagnetic lipolysis and semicircular lipoatrophy of the thighs. Ann Dermatol Venereol 2006; 133:577-580.

16 Verschaeve L, Maes A: In vitro investigations related to the hypothesis that lipoatrophia semicircularis finds its origin in electro-stimulation. J Appl Toxicol 2009;29:478-482.

17 Gomez-Espejo C, Perez-Bernal A, CamachoMartinez F: A new case of semicircular lipoatrophy associated with repeated external microtraumas and review of the literature. J Eur Acad Dermatol Venereol 2005;19:459-461.

18 Cho SB, Bae BG, Kwon JE, Park JM, Bang D: Ultrastructural features of lipoatrophia semicircularis in Behçet's disease. Clin Exp Rheumatol 2010;28(4 suppl 60):S97-S98.

19 Pomares-Roche JM, Arrizabalaga-Clemente P: Lipoatrophy semicircularis. Med Clin (Barc) 2008;130:213-215.

20 Senecal S, Victor V, Choudat D, Hornez-Davin S, Conso F: Semicircular lipoatrophy: 18 cases in the same company. Contact Dermatitis 2000;42:101-102.

21 Reinoso-Barbero L, Gonzalez-Gomez MF, Belanger-Quintana D, Piñaga-Solé M, Fernández-Fernández $\mathrm{M}$, Garrido-Astray $\mathrm{MC}$, Capapé-Aguilar A, Mota-Olmeda A, DíazGarrido R, Gómez-Gallego F, Bandrés-Moya F, Sanz-González J: Case-control study of semicircular lipoatrophy, a new occupational disease in office workers. J Occup Health 2013;55:149-157.
22 Sanz P, Nogué S, Farrús X, María Molina J: Semicircular lipoatrophy in office workers. Med Clin (Barc) 2010;134:135-136.

23 Van Loock W: Avoiding lipoathrophia semicircularis in an office environment. 4th AsiaPacific Conference on Environmental Electromagnetics, Dalian, August 1-4, 2006, pp 76-81.

24 Boleira M, D’Acri A, Caramez C, Treu C: Lipoatrophia semicircularis. J Am Acad Dermatol 2011;64:AB41.

25 Maes A, Curvers B, Verschaeve L: Lipoatrophia semicircularis: an electromagnetic hypothesis. Electromagn Biol Med 2003;22: 183-193.

-26 Van Loock W: Lipoatrophia semicircularis: an electromagnetic myth. 7th International Symposium on Electromagnetic Compatibility and Electromagnetic Ecology, St Petersburg, 2007, pp 319-322.

27 Verschaeve L, Maes A: Support for the hypothesis that electro-stimulation is responsible for lipoatrophia semicircularis. Med Hypotheses 2009;73:802-806.

28 Herane MI, Urbina F, Sudy E: Lipoatrophia semicircularis: a compressive lipoatrophy consecutive to persistent mechanical pressure. J Dermatol 2007;34:390-393.

29 Reinoso-Barbero L, Diaz R, Pinaga M, Bravo MF: Semicircular lipoatrophy. The case of a very tall worker. An Sist Sanit Navar 2012;35: 313-315.

30 http://www.gd-emf-consulting.be/rapporten/ESD\%20en\%20RIBBELDIJEN.pdf. 